\title{
Anesthetic management of a parturient with segmental neurofibromatosis
}

\author{
Kevin Blackney, Mark J. McKeen* and Yvonne Lai
}

*Correspondence: mmckeen@partners.org

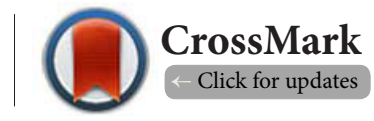

Massachusetts General Hospital Department of Anesthesia, Critical Care and Pain Medicine, Boston, USA.

\begin{abstract}
Segmental neurofibromatosis is a rare, but likely under reported form of neurofibromatosis. The traditional definition is that of dermatologic manifestations of neurofibromatosis, including neurofibromas and café-au-lait macules, confined to one segment of the body as a result of a somatic mutation. However, this definition has expanded to include deeper tissue and systemic involvement. To date, there is limited description with regards to anesthetic management of obstetric patients with this condition. Here we report on a patient with segmental neurofibromatosis who presented for induction of labor that was soon complicated by conversion to cesarean delivery for a non-reassuring fetal heart rate tracing.
\end{abstract}

Keywords: Segmental neurofibromatosis, neuraxial, obstetric anesthesia, epidural, spinal

\section{Introduction}

Segmental neurofibromatosis (SNF) is a rare form of neurofibromatosis with an estimated prevalence of 1 in 40,000 [1]. It typically presents with isolated dermatologic findings of neurofibromatosis type 1 (NF1), although bilateral, deep tissue, multi-segmental, and systemic involvement is possible [2-7]. These issues have direct implications on the anesthetic management of obstetric patients with SNF as presented here. We obtained the patient's permission prior to submitting this report.

\section{Case report}

A 41 year-old female, G2P0, diagnosed with SNF by her dermatologist, presented for induction of labor for oligohydramnios at 39 weeks gestation. Her pregnancy was uneventful prior to her admission to the labor and delivery floor. The patient's initial diagnosis of SNF was made several years prior and was based on left axillary freckling with multiple tan macules and patches, as well as a patch on her left breast with a dark brown macule. She had not had any prior neuraxial imaging, and evaluation of her condition was limited to dermatology and a genetics assessment.

Upon arrival, the patient underwent an initial assessment by the anesthesia team including a standard history and physical exam. Her past medical history of SNF was unique to her anesthesia providers, which prompted a review. A traditional definition of SNF was found that described strictly cutaneous manifestations localized to one area of the body. While a more in-depth literature review of SNF was initiated which later revealed case reports of neuraxial involvement, her induction was started with misoprostol. Once a more extensive understanding of SNF was obtained, the patient was re-evaluated, focusing on more extensive questioning of her neurologic status. She denied any leg weakness, paresthesias, back pain, dizziness, or headaches. She was observed walking without difficulty and showed no evidence of neurologic compromise on physical exam. Furthermore, she denied any oropharyngeal symptoms that would indicate a mass lesion or potential airway obstruction. Neuraxial imaging was strongly considered by the anesthesia team; however, given that she had no neurologic symptoms and that her induction had already been initiated, the decision was made to proceed without any further workup.

Induction of labor continued with misoprostol, but after receiving her second dose, the fetus developed persistent, late decelerations, and the decision was made to proceed with urgent cesarean delivery. In this setting, the anesthesia team carefully evaluated the risks and benefits of neuraxial vs. general anesthesia. Because central nervous system involvement of SNF does not appear to be common and she did not manifest any neurological symptoms, the team decided to proceed with neuraxial anesthesia despite the absence of neuroimaging. A thorough discussion while obtaining informed consent was conducted with the patient as she was prepped for surgery, focusing on higher risks of nerve injury, hematoma or failed spinal anesthesia. Therefore, since the patient had not yet received an epidural catheter, a standard single shot spinal injection with hyperbaric bupivacaine was successfully 
performed and she had an otherwise uneventful cesarean delivery. The remainder of her hospital stay was unremarkable and she was discharged home with no change from her preoperative neurological status.

\section{Discussion}

Neurofibromatosis is a collection of genetically distinct disorders with the commonality of benign tumor formation on nervous tissue of neural crest cell origin $[8,9]$. This is one of the most common human mutations with many cases representing a new genetic anomaly [1]. In 1982, Riccardi defined eight categories of the disease, most notably neurofibromatosis type 1 (NF1), i.e., Von Recklinghausen Disease and neurofibromatosis type 5, i.e., segmental neurofibromatosis (SNF) [10]. He described SNF to be neurofibromas in a single, unilateral segment of the body without crossing the median line, and lacking familial history and any systemic involvement [11]. In 1987, Roth et al., expanded this definition to include other subtypes such as localization with deep tissue involvement, hereditary, and bilateral variations, in addition to the traditional form [6].

NF1 is the most common type of neurofibromatosis with an incidence of 1 in 3,000 and a prevalence in pregnancy of $0.008 \%$. A recent article by Terry et al., showed evidence of higher rates of gestational hypertension, cerebrovascular complications, and cesarean delivery in patients with NF1 [12]. In addition to the characteristic presence in the neuraxis, Hirsch et al., showed that $5 \%$ of patients with neurofibromatosis also have neurofibromas in the oropharynx that could hinder airway management [13].

SNF is a rare form of neurofibromatosis, although it is believed to be under-diagnosed and underreported [9]. SNF and NF1 are both the result of alterations of the NF1 gene. They differ in that SNF results from a postzygotic somatic mutation leading to genetic mosaicism within the affected individual and is not inherited, as opposed to NF1 which is a germline mutation and is transmitted in an autosomal dominant fashion $[\mathbf{1}, \mathbf{9}, \mathbf{1 1}, \mathbf{1 4}, \mathbf{1 5}]$. In terms of our patient, we found limited relevant literature regarding anesthetic management in the obstetric setting. Our literature search revealed several case reports and review articles that we considered throughout the perioperative period. The only discussion of SNF in the peripartum setting specifically was a case report of a patient diagnosed during pregnancy with bilateral SNF. This patient's lesions increased in size prior to delivery, a finding that is commonly seen in NF1 as well [3].

Our patient, like most peripartum patients, requested neuraxial anesthesia for delivery. The initial plan was for epidural placement during labor for vaginal delivery. As the patient's presentation was for an induction of labor, we considered neuraxial imaging prior to placement as is recommended for other forms of neurofibromatosis. Our concern was that although her cutaneous lesions were unilateral and at the thoracic level, there are case reports of multiple segment involvement and also of crossing the midline [2-7]. Imaging, however was not obtained as described above. NF1 is known to have central nervous system involvement with neurofibromas [8]. These can lead to challenging placement of neuraxial anesthetics by creating an anatomical obstruction, or if a mass lesion is present in the brain, this could raise intracranial pressure, thus contraindicating subarachnoid penetration [16]. This risk is heightened in pregnancy as lesions tend to enlarge due to hormonal changes $[3,17]$. Additional concerns regarding local involvement include nerve compression due to hemorrhage into a penetrated neurofibroma and the potential to spread mutated cells through the needle track during neuraxial placement [18]. With regards to SNF specifically, in review of literature, there are several case reports of central nervous system and large peripheral nervous system involvement which must be considered before pursuing neuraxial anesthesia [19-24]. We believe there is potential for complications and can only be safely ruled out with more extensive evaluation.

Had we had more time, we would have advocated for neuraxial imaging, preferably magnetic resonance imaging (MRI), prior to induction of labor. Many recommend formal imaging for NF1 prior to active labor to assess for these potential risks [17]. If a patient is in active labor and requesting neuraxial anesthesia, an MRI would not be practical due to the time for imaging. In this situation, we feel neuraxial anesthesia can be pursued after a thorough discussion of the risks while obtaining informed consent. Ideally, we would have coordinated with our obstetricians prior to presentation for induction of labor in order to perform a complete evaluation of this patient, including imaging of the neuraxis, with an MRI. In the antepartum setting, identifying patients at risk and conducting a thorough assessment prior to the onset of labor is essential [16]. As stated above in our case, based on the current disease definition and given that CNS involvement appears to be rare with SNF, we felt that it was safer to proceed with spinal anesthesia for our patient's urgent cesarean delivery as opposed to general anesthesia.

In terms of obstetric outcomes, patients with NF1 have higher rates of cesarean delivery [12]. Recent studies in rat models have linked this finding to mutations in the NF1 gene and an associated vasculopathy $[\mathbf{2 5}, \mathbf{2 6}]$. To date, we could not find any link between this pathology and SNF, though there was a case report of neurofibroma localization to the female genitourinary tract, which could present challenges for the obstetric patient [27]. While our patient had early onset of late decelerations, we believe this was more likely related to her oligohydramnios and not a vasculopathy. However, we do feel there is the potential for fetal compromise in patients with SNF and that this should be considered in their peripartum management.

\section{Conclusion}

Segmental neurofibromatosis is a rare variant within the 
neurofibromatosis class of syndromes. When caring for these patients in the peripartum setting, it is important to perform a thorough preoperative evaluation, to consider neuraxial imaging, and to be aware of the potential anesthetic complications associated with this disease.

\section{Competing interests}

The authors declare that they have no competing interests.

Authors' contributions

\begin{tabular}{|l|c|c|c|}
\hline Authors' contributions & KAB & MJM & YL \\
\hline Research concept and design & $\checkmark$ & -- & -- \\
\hline Collection and/or assembly of data & $\checkmark$ & -- & -- \\
\hline Data analysis and interpretation & $\checkmark$ & -- & -- \\
\hline Writing the article & $\checkmark$ & -- & -- \\
\hline Critical revision of the article & $\checkmark$ & $\checkmark$ & -- \\
\hline Final approval of article & $\checkmark$ & $\checkmark$ & $\checkmark$ \\
\hline Statistical analysis & -- & -- & -- \\
\hline
\end{tabular}

Publication history

Editors: Andra D. DiStefano, University of Maryland School of Medicine, USA.

Narasimhan Jagannathan, Northwestern University, USA.

Senior Editor: Michael Paech, University of Western Australia, Australia.

Received: 28-Apr-2014 Final Revised: 05-Jun-2014

Accepted: 12-Jun-2014 Published: 19-Jun-2014

\section{References}

1. Riccardi VM. Von Recklinghausen neurofibromatosis. N Engl J Med. 1981; 305:1617-27. | Article | PubMed

2. Kumar S and Kumar RP. Multiple-segmental neurofibromatosis. Indian J DermatolVenereolLeprol. 2004, 70:361-3. | Article

3. Maldonado Cid P, Sendagorta Cudos E, Noguera Morel L and Beato Merino MJ. Bilateral segmental neurofibromatosis diagnosed during pregnancy. Dermatol Online J. 2011; 17:6. I Article I PubMed

4. Mansur AT, Goktay F, Akkaya AD and Gunes P. Segmental neurofibromatosis: report of $\mathbf{3}$ cases. Cutis. 2011; 87:45-50. | Article | PubMed

5. Pascual-Castroviejo I, Pascual-Pascual SI, Velazquez-Fragua R, Viano $\mathrm{J}$ and Lopez-Gutierrez JC. [Segmental neurofibromatosis in children. Presentation of 43 patients]. Rev Neurol. 2008; 47:399-403. | Article | PubMed

6. Roth RR, Martines R and James WD. Segmental neurofibromatosis. Arch Dermatol. 1987; 123:917-20. | Article I PubMed

7. Toy B. Segmental neurofibromatosis. Dermatol Online J. 2003; 9:26. | Article I PubMed

8. Ferner RE. The neurofibromatoses. Pract Neurol. 2010; 10:82-93. | Article | PubMed

9. Ruggieri M and Huson SM. The clinical and diagnostic implications of mosaicism in the neurofibromatoses. Neurology. 2001; 56:1433-43. Article I PubMed

10. Morais P, Ferreira O, Bettencourt H and Azevedo F. Segmental neurofibromatosis: a rare variant of a common genodermatosis. Acta Dermatovenerol Alp Pannonica Adriat. 2010; 19:27-9. | Pdf I PubMed

11. Gabhane SK, Kotwal MN and Bobhate SK. Segmental neurofibromatosis: a report of 3 cases. Indian J Dermatol. 2010; 55:105-8. | Article | PubMed Abstract | PubMed Full Text
12. Terry AR, Barker FG, 2nd, Leffert L, Bateman BT, Souter I and Plotkin SR. Neurofibromatosis type 1 and pregnancy complications: a populationbased study. Am J Obstet Gynecol. 2013; 209:46 e1-8. I Article I PubMed

13. Hirsch NP, Murphy A and Radcliffe JJ. Neurofibromatosis: clinical presentations and anaesthetic implications. Br J Anaesth. 2001; 86:55564. | Article | PubMed

14. Adigun CG and Stein J. Segmental neurofibromatosis. Dermatol Online J. 2011; 17:25. | Article | PubMed

15. Tinschert S, Naumann I, Stegmann E, Buske A, Kaufmann D, Thiel G and Jenne DE. Segmental neurofibromatosis is caused by somatic mutation of the neurofibromatosis type 1 (NF1) gene. Eur J Hum Genet. 2000; 8:455-9. | Article | PubMed

16. Sakai T, Vallejo MC and Shannon KT. A parturient with neurofibromatosis type 2: anesthetic and obstetric considerations for delivery. Int J Obstet Anesth. 2005; 14:332-5. I Article I PubMed

17. Spiegel JE, Hapgood A and Hess PE. Epidural anesthesia in a parturient with neurofibromatosis type 2 undergoing cesarean section. Int J Obstet Anesth. 2005; 14:336-9. I Article I PubMed

18. Ambardekar AP, Ganesh A and Schwartz AJ. The value of ultrasound in the safe care of a patient with neurofibromatosis. Anesthesiology. 2013; 118:1206. | Article | PubMed

19. Chebel S, Ben Yahia S, Boughammoura-Bouatay A, Salem R, Golli M, Khairallah $\mathrm{M}$ and Frih-Ayed $\mathrm{M}$. A clinical and magnetic resonance spectroscopy study of a brain tumor in a patient with segmental neurofibromatosis. Neurochirurgie. 2010; 56:297-302. | Article | PubMed

20. Kurimoto M, Mizumaki Y, Fukuda O, Hayashi N, Kuwayama N and Endo S. Giant plexiform neurofibroma and suboccipital meningocele manifesting as segmental neurofibromatosis. Neurol Med Chir (Tokyo). 2008; 48:271-4. | Article | PubMed

21. Muthukumar N. Segmental neurofibromatosis-induced spinal cord compression. Case report. J Neurosurg. 2001; 95:236-8. | Article | PubMed

22. Pascual-Castroviejo I, Pascual-Pascual SI and Viano J. Segmental neurofibromatosis type 1 (NF1) associated with Cobb syndrome: case report. Neuropediatrics. 2008; 39:341-3. | Article I PubMed

23. Sieb JP and Schultheiss R. Segmental neurofibromatosis of the sciatic nerve: case report. Neurosurgery. 1992; 31:1122-5; discussion 1125. Article I PubMed

24. Trocchia A, Reyes A, Wilson J and Les K. A rare case of segmental neurofibromatosis involving the sciatic nerve. Am J Orthop (Belle Mead NJ). 2010; 39:E42-5. | Pdf | PubMed

25. Bajaj A, Li QF, Zheng $Q$ and Pumiglia K. Loss of NF1 expression in human endothelial cells promotes autonomous proliferation and altered vascular morphogenesis. PLoS One. 2012; 7:e49222. | Article | PubMed Abstract | PubMed Full Text

26. Lasater EA, Li F, Bessler WK, Estes ML, Vemula S, Hingtgen CM, Dinauer MC, Kapur R, Conway SJ and Ingram DA, Jr. Genetic and cellular evidence of vascular inflammation in neurofibromin-deficient mice and humans. J Clin Invest. 2010; 120:859-70. | Article | PubMed Abstract | PubMed Full Text

27. Gersell DJ and Fulling KH. Localized neurofibromatosis of the female genitourinary tract. Am J Surg Pathol. 1989; 13:873-8. | Article | PubMed

\section{Citation:}

Blackney K, McKeen MJ and Lai Y. Anesthetic management of a parturient with segmental neurofibromatosis. J Anesthesiol Clin Sci. 2014; 3:5. http://dx.doi.org/10.7243/2049-9752-3-5 